\title{
BISPHENOL A INFLUENCES OESTROGEN- AND THYROID HORMONE-REGULATED THYROID HORMONE RECEPTOR EXPRESSION IN RAT CEREBELLAR CELL CULTURE
}

\author{
Virág SOMOGYI ${ }^{1}$, Tamás L. HORVÁTH ${ }^{2,3}$, István TÓTH ${ }^{1}$, Tibor BARTHA ${ }^{1}$, \\ László Vilmos FrENYÓ ${ }^{1}$, Dávid Sándor KISS ${ }^{1}$, Gergely JóCSÁK ${ }^{1}$, Annamária KERTI ${ }^{2}$, \\ Frederick NAFTOLIN ${ }^{4}$ and Attila ZSARNOVSZKY ${ }^{2,3^{*}}$ \\ ${ }^{1}$ Department of Physiology and Biochemistry, University of Veterinary Medicine, \\ Budapest, Hungary; ${ }^{2}$ Department of Animal Physiology and Animal Health, \\ Faculty of Agricultural and Environmental Sciences, Szent István University, \\ Páter Károly u. 1, H-2100 Gödöllő, Hungary; ${ }^{3}$ Section of Comparative Medicine, \\ Yale University School of Medicine, New Haven, CT, USA; \\ ${ }^{4}$ Reproductive Biology Research, New York University, New York, NY, USA
}

(Received 4 August 2016; accepted 2 November 2016)

Thyroid hormones (THs) and oestrogens are crucial in the regulation of cerebellar development. TH receptors (TRs) mediate these hormone effects and are regulated by both hormone families. We reported earlier that THs and oestradiol $\left(\mathrm{E}_{2}\right)$ determine TR levels in cerebellar cell culture. Here we demonstrate the effects of low concentrations $\left(10^{-10} \mathrm{M}\right)$ of the endocrine disruptor $(\mathrm{ED})$ bisphenol A (BPA) on the hormonal (THs, $\mathrm{E}_{2}$ ) regulation of $\mathrm{TR} \alpha, \beta$ in rat cerebellar cell culture. Primary cerebellar cell cultures, glia-containing and glia-destroyed, were treated with BPA or a combination of BPA and $\mathrm{E}_{2}$ and/or THs. Oestrogen receptor and TH receptor mRNA and protein levels were determined by real-time qPCR and Western blot techniques. The results show that BPA alone decreases, while BPA in combination with THs and/or $\mathrm{E}_{2}$ increases TR mRNA expression. In contrast, BPA alone increased receptor protein expressions, but did not further increase them in combination with THs and/or $\mathrm{E}_{2}$. The modulatory effects of BPA were mediated by the glia; however, the degree of changes also depended on the specific hormone ligand used. The results signify the importance of the regulatory mechanisms interposed between transcription and translation and raise the possibility that BPA could act to influence nuclear hormone receptor levels independently of ligand-receptor interaction.

Key words: Endocrine disruptors, thyroid receptor, transcription, translation, bisphenol A, rat cerebellum

Thyroid hormones (THs) and oestrogens (mostly $17 \beta$-oestradiol, $\mathrm{E}_{2}$ ) play critical roles in the regulation of central nervous system (CNS) development, in-

*Corresponding author; Zsarnovszky.Attila@mkk.szie.hu; Phone: 0036 (28) 522-062/1620 (office); 0036 (30) 665-3717 (mobile); Fax: 0036 (28) 522-062 
cluding the cerebellum. Effects of these hormones are mediated by numerous mechanisms, including, but most probably not limited to, cognate receptors (oestrogen receptors alpha and beta $[\mathrm{ER} \alpha, \beta]$ and $\mathrm{TH}$ receptors alpha and beta $[\mathrm{TR} \alpha, \beta])($ Belcher and Zsarnovszky, 2001; Fan et al., 2010), membrane-linked ligand-receptor complexes (Belcher, 2008; Leonard, 2008) and crosstalk between genomic and/or non-genomic $\mathrm{E}_{2}$ - and $\mathrm{TH}$-activated intracellular signalling pathways (Vasudevan et al., 2001; Zhao et al., 2005). Previously we demonstrated that $E_{2}$ and THs alone or in combination determine TR $\alpha, \beta$ and ER $\beta$ mRNA and protein expression levels in primary cerebellar cell cultures (Scalise et al., 2012). In addition to hormone effects, we also showed that the astroglia (glia) may be an additional site of these actions. Based on the available literature and our studies, endocrine disruptor- (ED) induced disturbance of the physiological synchrony between $\mathrm{E}_{2}$ and THs during cerebellar development could be more pervasive and far-reaching than currently appreciated, and merits investigation (Somogyi et al., 2011).

Oestrogenic ED chemicals, such as phytoestrogens or environmental pollutants are selective ER modulators and can act as agonists or antagonists of the hormones in question. During development, EDs can influence normal hormonal homeostasis and lead to immediate and/or lifelong consequences (e.g., Zsarnovszky et al., 2007; Miodovnik et al., 2014). With regard to ED effects in the cerebellum, we have previously shown that bisphenol A (BPA) rapidly activates ERK1/2 in primary cerebellar cell cultures (Wong et al., 2003) and also after injection of BPA into the cerebella of newborn rat pups (Zsarnovszky et al., 2005). These effects were concentration dependent, with a U-shaped concentrationresponse curve, which could indicate compound actions of BPA. In support of these findings, Mathisen et al. (2013) described that perinatal BPA exposure increased Pax6 (transcription factor playing a role in granule cell development and migration) in newborn mice cerebella and in cerebellar cell cultures. In the hippocampus, BPA modulated dendritic morphogenesis via effects on ER (Xu et al., 2014). Likewise, BPA also promoted dendritic growth in maturing cerebellar Purkinje cells (Shikimi et al., 2004). This is consonant with our previous results (Wong et al., 2003; Zsarnovszky et al., 2005).

In addition, BPA can alter thyroid-specific gene expression (Gentilcore et al., 2013) and functions (Zoeller et al., 2005; Iwamuro et al., 2006; Delfosse et al., 2014). Our studies indicated that the ratio of THs to $E_{2}$ in the CNS is critical for the regulation of nuclear receptor expression (Scalise et al., 2012).

While a growing body of evidence indicates that EDs, including BPA, interfere with CNS development, the exact mode of BPA action, and how it alters TR expression levels, is not clear. In the present study we examined to what extent BPA alone or in combination with THs and/or $\mathrm{E}_{2}$ alters TR $\alpha, \beta$ mRNA and protein expression levels in primary cerebellar cell cultures. We also examined 
whether the glia could modulate hormone and/or BPA effects on TR mRNA and protein expression levels.

\section{Materials and methods}

Hormones and BPA were obtained from Sigma Aldrich Ltd., Hungary.

\section{Animals}

Since neither previous studies nor our own results indicated sex differences in the developing rat cerebellum in any of the parameters examined in this study, both male and female Sprague-Dawley rat pups (body weight: 18-20 g) were used. Timed pregnant Sprague-Dawley rats (Charles River Laboratories, Germany; $n=60$ ) were obtained from the vendor at least four days before they gave birth. Animals were kept under standard laboratory conditions (temperature: 24 $25^{\circ} \mathrm{C}$; humidity: 55-60\%; room ventilation rate: 17 air changes per hour, with the animals protected from draughts; noise reduced to the possible minimum in the human hearing range, as well as in the ultrasonic range), with tap water and regular rat chow ad libitum in a 12-h light, 12-h dark cycle. The date of the pups' birth was considered as postnatal day $0(\mathrm{P} 0)$. Animals were used for granule cell preparation on their $\mathrm{P} 7$ ( $\mathrm{n}=576$, i.e., $\mathrm{n}=6$ per each treatment group).

Following the guidelines established by the National Institutes of Health $(\mathrm{NIH})$, the use of animals was approved by the Animal Welfare Board at Szent István University, Faculty of Veterinary Science and were approved by the regional animal welfare authority (registry no.: XIV-I-001/2201-4/2012).

\section{Preparation of primary cerebellar cell cultures}

Primary cerebellar cultures were prepared as described earlier (Wong et al., 2001) with modifications, as follows. Animals were sacrificed by quick decapitation and the cerebella removed. Cell cultures were prepared without enzymatic treatment and were maintained in serum- and steroid-free conditions as previously described (Wong et al., 2001). Cerebellar cell suspensions were diluted with culture medium to obtain 2300-2700 granule cells $/ \mathrm{mm}^{2}$ prior to testing. Cerebella of rat pups were seeded into separate culture dishes (i.e., 6 dishes per treatment, $n=6$ ). Astroglia in the cultures was identified by immunohistochemical labelling for the specific astroglia marker glial fibrillary acidic protein (GFAP), as we previously described and illustrated (Scalise et al., 2012).

\section{Treatments}

For analysis of mature (post-mitotic) primary cerebellar granule cells in a glia-destroyed environment, a final concentration of $10^{-5} \mathrm{M}$ cytosine $\beta$-Darabinofuranoside (AraC; Sigma Aldrich Ltd., Hungary; Cat. \# 147-94-4) was 
added $24 \mathrm{~h}$ after seeding to inhibit the growth and proliferation of non-neuronal cells (Glia- cultures). In contrast, no AraC was added to the media for analysis of neurones grown in a glia-containing environment (Glia+ cultures). The presence or absence of glia in the cultures was verified and illustrated as shown earlier (Scalise et al., 2012). Cultures were treated with either of the following hormones (at physiologically relevant concentrations, as described below) and/or bisphenol A, 7 days after seeding and $6 \mathrm{~h}$ (for qPCR) or $18 \mathrm{~h}$ (for Western blot) before harvesting: $17 \beta$-oestradiol $\left(\mathrm{E}_{2}, 1.16 \times 10^{-10} \mathrm{M}\right.$, Sigma Aldrich Ltd., Hungary, Cat. \# E2758); 3,3',5-triiodo-L-thyronine (T3, $0.92 \times 10^{-9} \mathrm{M}$, Sigma Aldrich Ltd., Hungary; Cat. \# T2877); L-thyroxine (T4, $65 \times 10^{-9} \mathrm{M}$, Sigma Aldrich Ltd., Hungary; Cat \# T1775); $\mathrm{E}_{2}+\mathrm{T} 3$ or $\mathrm{E}_{2}+\mathrm{T} 4$ (at concentrations described above); bisphenol A (BPA, $10^{-10} \mathrm{M}$, Sigma Aldrich Ltd., Hungary; Cat \# $\mathrm{A} 239658) ; \mathrm{BPA}+\mathrm{E}_{2} ; \mathrm{BPA}+\mathrm{T} 3 ; \mathrm{BPA}+\mathrm{E}_{2}+\mathrm{T} 3 ; \mathrm{BPA}+\mathrm{T} 4 ; \mathrm{BPA}+\mathrm{E}_{2}+\mathrm{T} 4$; the latter BPA-containing combined treatments were carried out in both Gliaand Glia+ groups. Cultures without hormone treatments were included in both Glia+ and Glia- groups (non-treated control, ntC). The applied concentration of BPA $\left(10^{-10} \mathrm{M}\right)$ was chosen based on our previous experiments (Wong et al., 2003) as follows: The biphasic effects of $E_{2}$ and BPA at the low concentration range $\left(10^{-12}\right.$ to $\left.10^{-9} \mathrm{M}\right)$ were assumed to act at two binding sites, one stimulatory with a high affinity and one with a lower affinity that inhibits the effect of the first site. Based on the observed similarity in effect at each concentration it was also assumed that neither of the two sites distinguishes between $E_{2}$ and BPA. Thus, data points were fit with the Hill-type equation:

$$
\text { Effect=maximal stimulation } \frac{1}{1+\left(\frac{E C 50 \text { stim }}{[C]}\right)^{H 1}} \frac{1}{1+\left(\frac{[C]}{E C 50: \text { nhib }}\right)^{H 2}}
$$

where $[\mathrm{C}]$ is the concentration of the ligand. A best fit of the equation to the data resulted from setting the maximum effect of the stimulatory site (maximal stimulation) at $110 \%$, with resulting values of 0.4 and 2 obtained for the stimulatory and the inhibitory Hill coefficients ( $\mathrm{H} 1$ and $\mathrm{H} 2)$, respectively. Under these conditions, $\mathrm{EC}_{50 \mathrm{Stim}}$ and $\mathrm{EC}_{50 \text { Inhib }}$ were determined as $8 \times 10^{-12} \mathrm{M}$ and $4 \times$ $10^{-9} \mathrm{M}$, respectively.

\section{Western blot studies}

Cell harvesting was performed as described by Wong et al. (2001). Samples were homogenized in (in mM) 20 Tris [(Tris-(hydroxymethyl)aminomethane, Reanal Cat. \# 34780-1-99-38) pH 7.6, $150 \mathrm{NaCl}$ (Sigma Aldrich Ltd., Hungary, Cat. \# S5886), 1 PMSF (Sigma Aldrich Ltd., Hungary, Cat. \# P7626), 1 EGTA (Sigma Aldrich Ltd., Hungary, Cat. \# E3889), 1 EDTA (Reanal-Ker Ltd., Hungary, Cat. \# 19012-1-38), 2.5 sodium pyrophosphate (Sigma Aldrich Ltd., Hun- 
gary, Cat. \# P8010), 1- $\beta$-glycerol phosphate (Sigma Aldrich Ltd., Hungary, Cat, \# G9891), and $1 \mathrm{Na}_{3} \mathrm{VO}_{4}$ (Sigma Aldrich Ltd., Hungary, Cat. \# S6508) plus $1 \mathrm{mg} / \mathrm{ml}$ Pefabloc (Fluka, Cat. \# 76307), $10 \mu \mathrm{g} / \mathrm{ml}$ leupeptin (Sigma Aldrich Ltd., Hungary, Cat. \# L2884), $10 \mu \mathrm{g} / \mathrm{ml}$ pepstatin (Sigma Aldrich Ltd., Hungary, Cat. \# P5318), $1 \mu \mathrm{g} / \mathrm{ml}$ aprotinin (Sigma Aldrich Ltd., Hungary, Cat. \# A3428), 1\% Triton X-100 (Sigma Aldrich Ltd., Hungary, Cat. \# T8787), and 0.05\% sodium deoxycholate (Sigma Aldrich Ltd., Hungary, Cat. \# D6750). Homogenates were sonicated for $5 \mathrm{sec}$ a total of 5 times and cleared by centrifugation at $14,000 \times \mathrm{g}$ for $1 \mathrm{~min}$ at $2{ }^{\circ} \mathrm{C}$. Protein concentrations were determined with a BCA protein assay kit (Pierce, Rockford, IL). Western blotting and densitometric analysis were performed by standard protocols (Wong et al., 2001); primary antibodies: antithyroid hormone receptor alpha, Abnova PAB-11276, dilution: 1:1,000; antithyroid hormone receptor beta, Abnova PAB-11277, dilution: 1:1000. Secondary antibodies: peroxidase labelled goat-anti rabbit IgG, Vector Laboratories, UK, Cat. \# PI-1,000, dilution: 1:2,000; peroxidase-labelled horse-anti mouse IgG, Vector Laboratories, UK, Cat. \# PI-2,000, dilution: 1:2,000). Immunoreactive bands were visualised onto preflashed X-ray film by enhanced chemiluminescence and analyzed by densitometric analysis. Optical densities were calculated as arbitrary units, normalised to the protein concentrations of samples, and to the ntC of Glia+. Results are presented as fold changes relative to the $\mathrm{ntC}$ of Glia + cultures. All data that have been presented are representative of at least three independent experiments $(n=6$ per treatment).

\section{Quantitative PCR measurements}

Total RNA was isolated from the cell samples using TRI Reagent (Invitrogen, Carlsbad, CA, USA, Cat. \# RT111) according to the manufacturer's instructions. Reverse transcription polymerase chain reaction was carried out following standard protocols. Primer sequences were as published by Billon et al. (2002) for TR $\alpha$, and Kariv et al. (2003) for TR $\beta$. Cellular gene expression was quantified by quantitative PCR reactions (qPCR; LightCycler 2.0, F. HoffmannLa Roche Ltd., Basel, Switzerland) using LightCycler DNA Master SYBRGReen I fluorescent dye (Hoffmann-La Roche Ltd., Basel, Switzerland, Cat. \# 12015099001). Aliquots of cDNAs were dispensed according to the manufacturer's instructions. QPCR cycles and controls were planned according to the manufacturer's instructions and were optimised for each primer pair. Amplified products were identified by agarose gel electrophoresis, melting point and sequence analysis (Applied Biosystems ABI 3100 Genetic Analyzer, Agricultural Biotechnology Centre, Gödöllö, Hungary). Real-time PCR threshold cycle (Ct) data were analysed using the REST-XL software version 2.0. The target $\mathrm{Ct}$ of each sample was normalized to the $\mathrm{Ct}$ of the reference (housekeeping) gene (rat cytoplasmic beta actin) in the same sample. Differences in the $\mathrm{Ct}$ values were converted into relative amounts of mRNA based on the assumption of am- 
plification efficiency $=2.0$. Results are presented as fold changes relative to the $\mathrm{ntC}$ of Glia+ cultures (i.e., further normalised to the ntC of Glia + ).

\section{Data analysis}

All data that have been presented are representative of at least three independent measurements. Statistical analyses were conducted using Excel (Microsoft, Microsoft Co., Redmond, WA, USA) and GraphPad Prism version 4 (GraphPad Software, San Diego, CA), by means of one-way ANOVA with Tukey's multiple comparison test. The level of statistical significance in differences between treatment groups as shown in the figures is $\mathrm{P}<0.05$.

\section{Results}

\section{General observations}

The results of hormone treatments were concordant with those we previously described (Scalise et al., 2012), so they will not be the major focus of this report; rather, these non-BPA-results are used as the reference base for the comparison between the effects of BPA alone and in combination with either $\mathrm{E}_{2}$ and/or THs.

In general, transcriptional activity was higher in Glia- cultures compared to ntC [Glia+] (Figs 1 and 3). Regardless of the glia, in BPA-treated cultures receptor mRNA levels were lower than in ntCs (Figs 1 and 3; columns A vs. B and $\mathrm{M} v s . \mathrm{N}$ ), however, combined treatment with BPA and either $\mathrm{E}_{2}$ or T3 resulted in increased receptor mRNA levels.

\section{Thyroid hormone receptor alpha $(T R \alpha)$}

TRa mRNA: Glia+ vs. Glia- (Fig. 1). Non-treated controls of Glia+ and Glia- significantly differed from each other, with higher TR $\alpha$ mRNA values in Glia- cultures. Such a difference was found between BPA [Glia+] and BPA [Glia-] as well. With respect to combined treatment groups, with the exception of T3 + BPA, an opposite effect was evident: TR $\alpha$ mRNA expression was lower in $\mathrm{E} 2+\mathrm{BPA}, \mathrm{T} 4+\mathrm{BPA}, \mathrm{E} 2+\mathrm{T} 3+\mathrm{BPA}$ and $\mathrm{E} 2+\mathrm{T} 4+\mathrm{BPA}$ cultures of Gliathan of Glia+.

TRa protein: Glia+ vs. Glia- (Fig. 2). In Glia+ cultures (Fig. 2 columns A-L), TR $\alpha$ receptor protein expression was maintained at significantly higher level than the $\mathrm{ntC}$ in all treatment groups, with the exception of E2 treatment. In contrast, in Glia- cultures, differences were found between groups treated with hormones only and those exposed to BPA as well. In Glia-, BPA treatment alone resulted in the expression of just as much receptor protein as BPA in combination with any of the hormones used. 


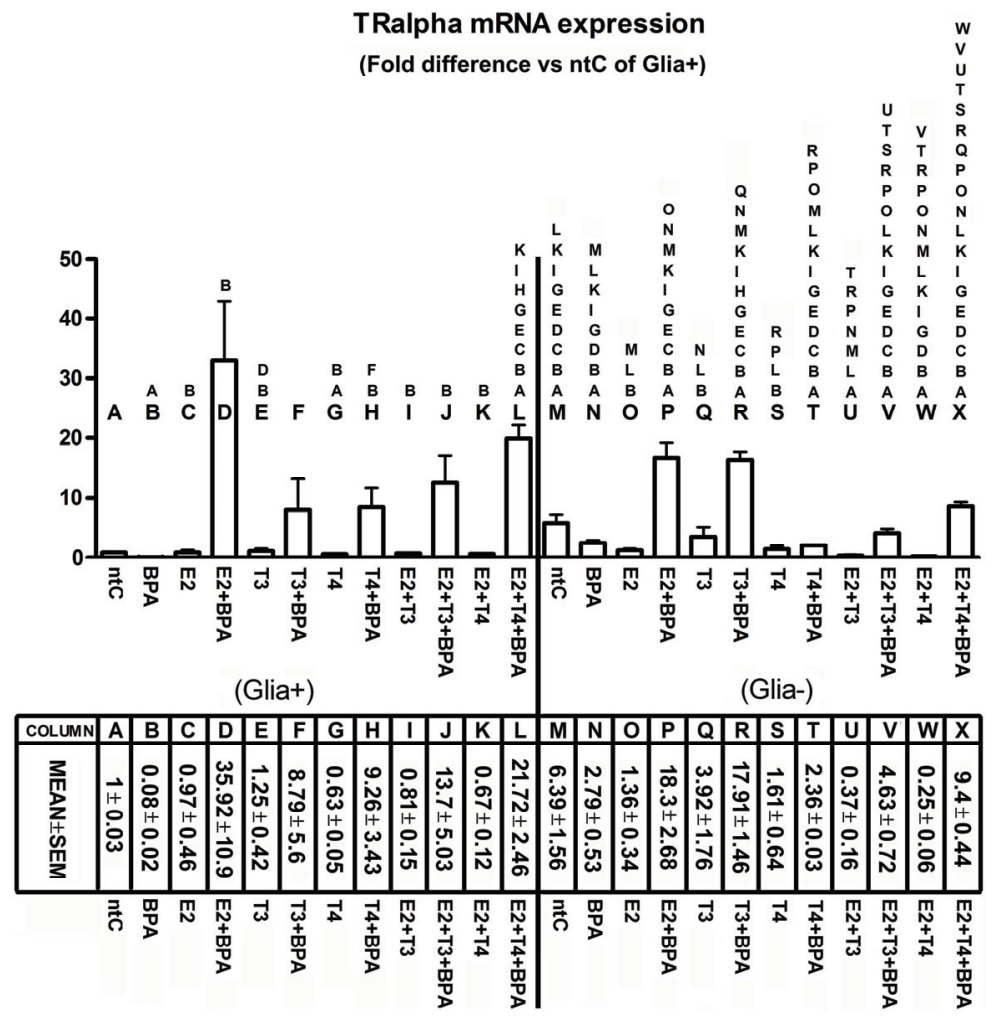

Fig. 1. TR $\alpha$ mRNA expression in primary cerebellar cell cultures treated with BPA, E2, TH or a combination of these substances. $\mathrm{X}$ axis shows experimental groups; $\mathrm{Y}$ axis shows fold changes versus non-treated control (ntC) of Glia+. In Glia+ cultures, BPA decreased TR $\alpha$ mRNA expression compared to the $\mathrm{ntC}$ and resulted in mRNA levels lower than after E2 or TH treatment. In Glia-cultures, however, TR $\alpha$ mRNA expressions were less different between the BPA- and THtreated groups. It is suggested that the glia may mediate BPA effects on transcription. All data that have been presented are representative of at least three independent measurements. Data show mean values \pm SEM. Statistical analyses were conducted using one-way ANOVA with Tukey's multiple comparison test $(n=6)$. The level of statistical significance in differences between experimental groups is $\mathrm{P}<0.05$. Smaller size letters above the columns indicate significant differences from columns labelled with larger size letters

\section{Thyroid hormone receptor beta (TR $\beta)$}

TRß mRNA: Glia+ vs. Glia- (Fig. 3). Differences between the members of the Glia+ and Glia- showed comparable trends, although distinct differences between analogous treatment subgroups may be remarkable and resemble, in many respects, our TR $\alpha$-related findings. Specifically, two exceptions were found from the above-stated phenomenon: (1) TR $\beta$ mRNA expression in T3 + BPA cultures was considerably higher in Glia- compared to Glia+ cultures; (2) in $\mathrm{E}_{2}+\mathrm{T} 3+$ BPA treatment groups, TR $\beta$ mRNA was significantly and prominently higher in Glia+ than in Glia-. 


\section{TRalpha protein expression \\ (Fold difference vs ntC of Glia+)}
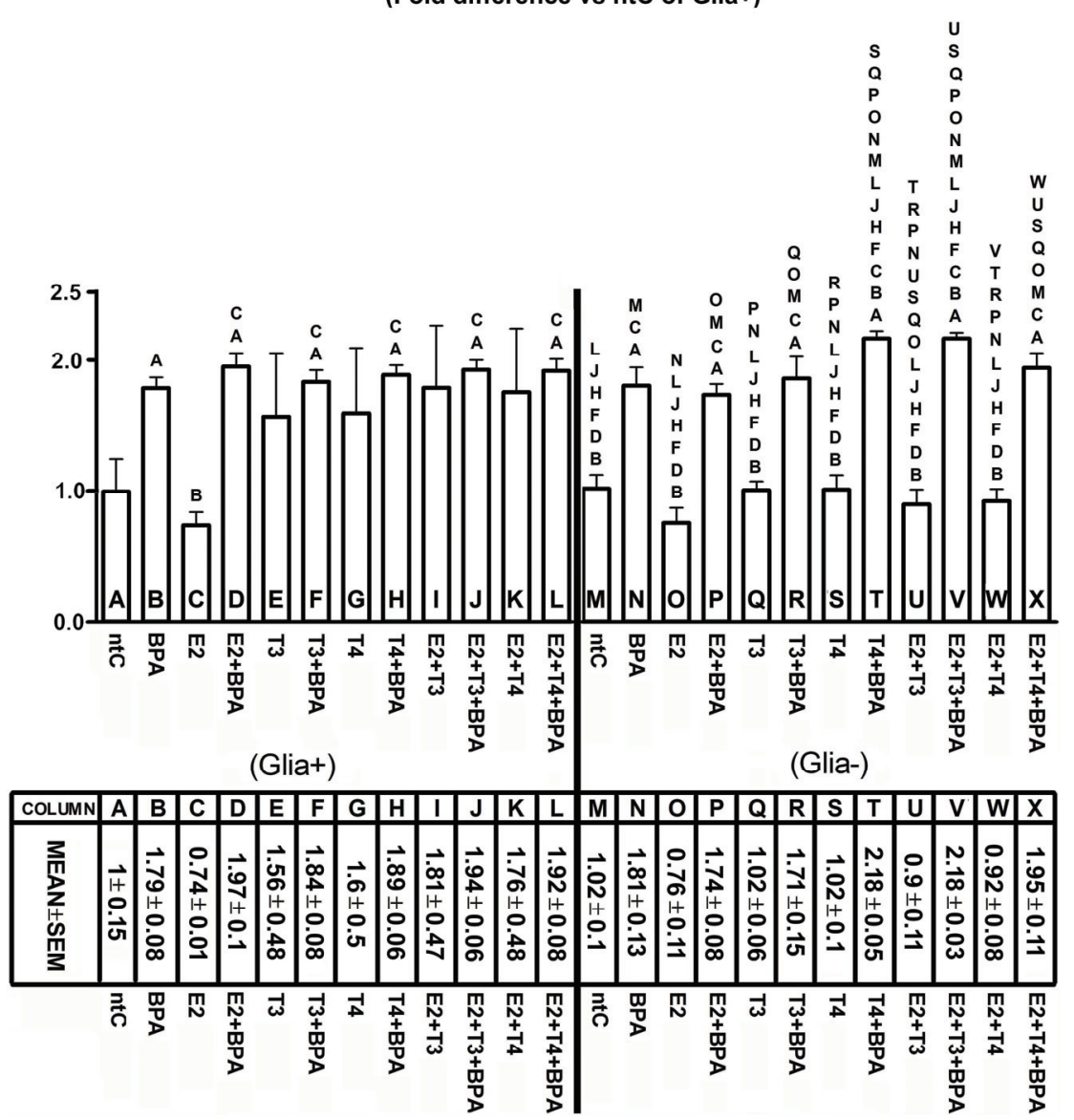

Fig. 2. TR $\alpha$ protein expression in primary cerebellar cell cultures treated with BPA, E2, TH or a combination of these substances. $\mathrm{X}$ axis shows experimental groups; $\mathrm{Y}$ axis shows fold changes versus non-treated control (ntC) of Glia+. In the presence of glia (Glia+), E2 alone did not cause a significant change compared to the ntC. In glia-destroyed environment (Glia-), significant differences were detected after BPA exposure compared to hormone-only treated cultures. All data that have been presented are representative of at least three independent measurements. Data show mean values \pm SEM. Statistical analyses were conducted using one-way ANOVA with Tukey's multiple comparison test $(n=6)$. The level of statistical significance in differences between experimental groups is $\mathrm{P}<0.05$. Smaller size letters above the columns indicate significant differences from columns labelled with larger size letters 


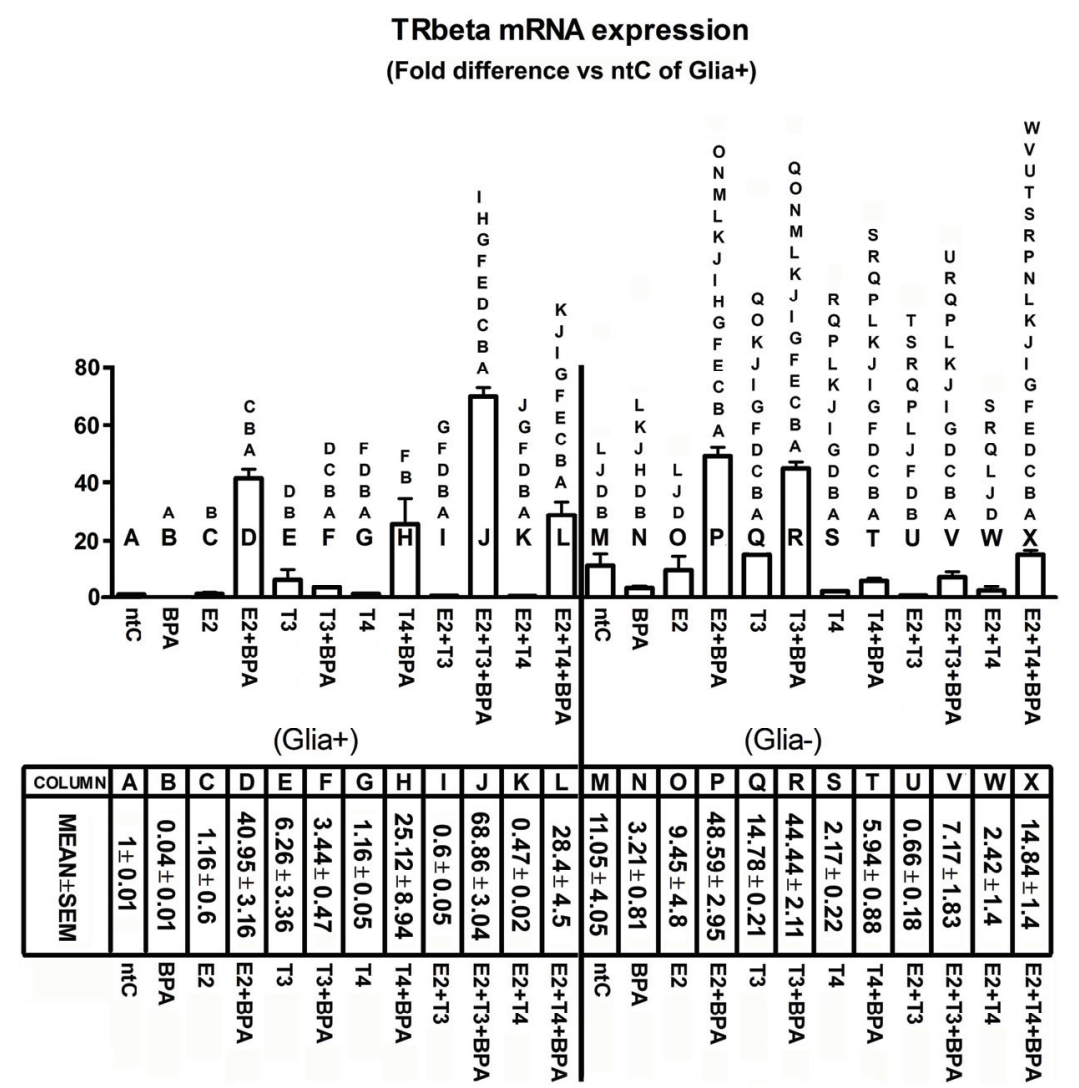

Fig. 3. TR $\beta$ mRNA expression in primary cerebellar cell cultures treated with BPA, E2, TH or a combination of these substances. $\mathrm{X}$ axis shows experimental groups; $\mathrm{Y}$ axis shows fold changes versus non-treated control (ntC) of Glia+. E2 and E2 + BPA effects do not seem to be gliadependent. However, when T3 was also added to the culture medium, significant differences were found between Glia+ and Glia- cultures. In Glia+ cultures, co-exposure of the cells to BPA and E2 or $\mathrm{E} 2+\mathrm{T} 3$ resulted in a nearly three-magnitude increase in TR $\beta$ transcription. All data that have been presented are representative of at least three independent measurements. Data show mean values \pm SEM. Statistical analyses were conducted using one-way ANOVA with Tukey's multiple comparison test $(n=6)$. The level of statistical significance in differences between experimental groups is $\mathrm{P}<0.05$. Smaller size letters above the columns indicate significant differences from columns labelled with larger size letters

TR $\beta$ protein: Glia + vs. Glia- (Fig. 4). TR $\beta$ protein expression measured in analogous subgroups of Glia+ and Glia- were relatively close to each other. TR $\beta$ protein expression levels were about twice as high in groups treated with BPA or BPA as well, than in cultures not treated with BPA, regardless of the presence or absence of glia. With respect to BPA exposure, clear glia effect on TR $\beta$ protein expression was only observed in analogous $E_{2}+B P A$ and $E_{2}+T 4+$ BPA groups. 


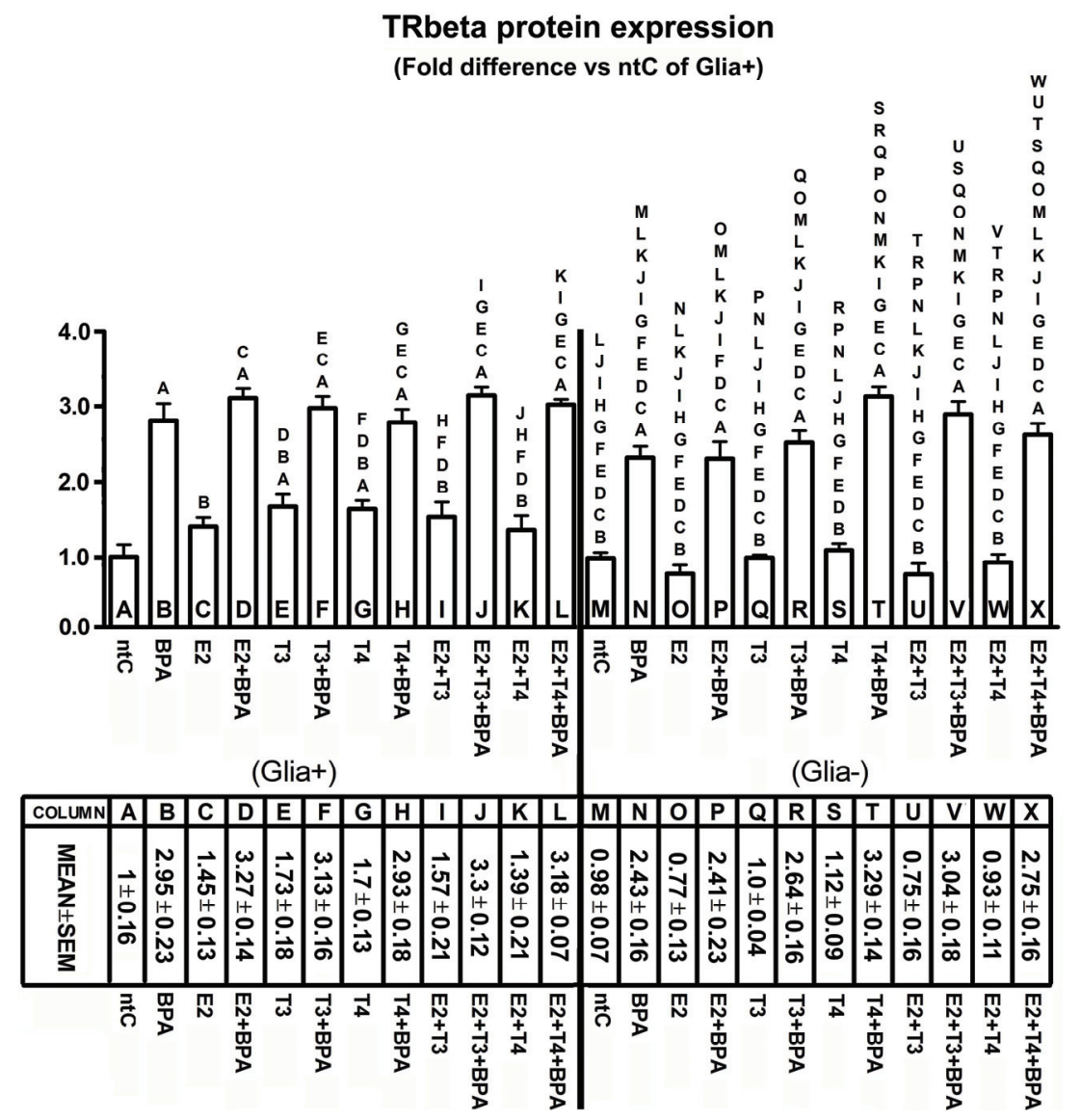

Fig. 4. TR $\beta$ protein expression in primary cerebellar cell cultures treated with BPA, E2, TH or a combination of these substances. $\mathrm{X}$ axis shows experimental groups; $\mathrm{Y}$ axis shows fold changes versus non-treated control (ntC) of Glia+. Receptor protein expression levels were about twice as high in groups treated with BPA or BPA as well, than in cultures not treated with BPA, regardless of the presence or absence of glia. Clear glia effect was only observed in analogous E2 + BPA (columns D vs. P) and E2 + T4 + BPA groups (columns L vs. X). All data that have been presented are representative of at least three independent measurements. Data show mean values $\pm \mathrm{SEM}$. Statistical analyses were conducted using one-way ANOVA with Tukey's multiple comparison test $(n=6)$. The level of statistical significance in differences between experimental groups is $\mathrm{P}<0.05$. Smaller size letters above the columns indicate significant differences from columns labelled with larger size letters

\section{Discussion}

The primary cerebellar cell culture has been extensively used for the study of cellular responses to various experimental cues. A question that we should address is with regard to the effect of glia in the adjustment of TR expression. In 
the present study, we compare endocrine effects in glia-containing versus gliadestroyed cultures. While differences between these groups is clearly the result of the presence or absence of glia, differences between treatment groups in Gliacultures carry the enigma of the share of glial TR levels in the entire cultured cell population. Since, however, granule neurones extremely outnumber sporadic and rudimentary glial cells in these cultures, it seems to be safe to interpret the treatment effects as if they were only exerted by neurones.

\section{Receptor mRNA levels}

Under in vitro circumstances it is especially interesting that BPA alone suppresses TR mRNA expression. This is supported by the findings of Sheng et al. (2012); however, earlier data also suggest that the suppressing effect of BPA on TRs may only be temporary, and symptoms that emerge later in life resulting from perinatal exposure to BPA may develop on the grounds of BPA-linked mechanisms indirectly (Xu et al., 2007). The observation that ntC values in Gliacultures superseded those measured in $\mathrm{ntC}$ Glia + suggests that the glia plays a role in the regulation of transcription, regardless of the type of receptor examined; even when cells were only treated with BPA alone, consequential decrease in TR transcription was more evident if the glia was present in the culture. While these observations are in concordance with previous results (Yamaguchi et al., 2006; Fauquier et al., 2014), our data also show that the effects of BPA on TR transcription are multifactorial and, in addition, differ depending on the presence or the absence of glia.

In contrast to the suppressing effect of BPA on receptor mRNA expression, the combination of BPA with any of the hormones provoked remarkably high transcriptional activity, regardless of the hormone used or the receptor examined. Such a robust ED effect has been reported earlier (Zhang et al., 2013), yet, this finding should still be alarming. To our knowledge, currently there is no explanation for this massive upregulation, although it is likely that the ability of BPA to act on TRs plays a role in the potentiation of transcription (Zoeller, 2005).

\section{Receptor protein levels}

It was generally observed that the effects of BPA or BPA in combination with $E_{2}$ and/or THs on translation (receptor protein expression) were less prominent than those found with regard to mRNA expression. Since the cellular effects of hormones are mostly mediated by their cognate receptors, this observation can explain why the biological effects of BPA-exposure could have remained masked or even unrecognised for a long time in spite of the dramatically increased transcriptional activity. Several studies suggested that exposure to EDs early in life leads to altered CNS development and functional deficiencies later in adulthood (Mathisen et al., 2013). The present results suggest that the final, al- 
tered outcome of hormonal signalling during ED exposure may only partly account for those anomalies, since the increased material and energy consumption by CNS cells in the process of enhanced transcription could also lead to energydeficient intracellular conditions that could be, at least in part, responsible for developmental deficiencies. This idea is consonant with the report of Nakagawa and Tayama (2000) that BPA toxicity caused a decrease in cellular ATP levels in hepatocytes.

The unproportional ED effects in transcription versus translation also indicate that regulatory mechanisms, interposed between transcription and translation, such as microRNA regulation, may also be affected by EDs, as indicated by Avissar-Whiting et al. (2010) and Tilghman et al. (2012). These mechanisms apparently play a crucial role in buffering ED effects downstream of transcription. This idea not only warrants further research of these mechanisms, but also shows that the potential vulnerability of such interposed regulatory mechanisms may determine the severity of ED effects.

\section{Thyroid hormone receptor alpha (TR $\alpha)$}

TRa mRNA: Glia+ vs. Glia- (Fig. 1). While differences between Glia+ and Glia-show comparable trends, it is noteworthy that in Glia+, BPA treatment alone resulted in lower TR $\alpha$ mRNA expression than $\mathrm{E}_{2}$ treatment alone, in contrast to the opposite findings in Glia-. Whether or not differences between treatment groups compared to their respective ntC followed similar trends (changes relative to each other), results indicate that the differences are due to glial effects. One possible mechanism underlying the afore-mentioned idea is that the glia may mediate BPA effects on the level of transcription in a T3-dependent manner, which is likely due to the ability of astroglia to convert T4 to T3 through deiodination (Leonard, 1988).

TR $\alpha$ protein: Glia+ vs. Glia-(Fig. 2). In Glia+, TR $\alpha$ receptor protein expression nearly doubled when cultures were exposed to any of the ligands used, with the exception of $E_{2}$. Thus, the potency of BPA, as a known oestrogenic chemical, to influence TR $\alpha$ expression more than $\mathrm{E}_{2}$ underlines the importance of BPA to be considered as a general nuclear receptor modulator, rather than just a chemical with oestrogenic or thyroid effect.

In Glia-, significant differences were found between groups treated with the hormones only and those exposed to BPA as well. This observation suggests that in the presence of glia, THs must be present for the maintenance of the afore-mentioned double levels of TR $\alpha$ protein expression (compared to $\mathrm{ntC}$ $[\mathrm{Glia}+]$ ), and that under such circumstances BPA does not further increase the TH-regulated TR $\alpha$ expression. The finding that in Glia- cultures these twofold $\mathrm{ntC}$ values were only detected if BPA was present alone or in combination with the hormones indicates that in neurones of Glia-, BPA (but not the hormones) determined the actual TR $\alpha$ protein expression values. 
TR $\alpha$ mRNA vs. TR $\alpha$ protein (Figs 1 and 2). The seemingly ligandindependent receptor protein expression levels were based on highly liganddependent transcriptional activity, especially in cultures treated with BPA or BPA in combination with any of the hormones. In Glia+, with the exception of the $n t C$ and the $E_{2}$ group, $T R \alpha$ protein expression levels were comparable (no significant differences), but were twofold compared to $\mathrm{ntC}$. This phenomenon means that these cell populations could either not produce more TR $\alpha$ protein (because of their limited capacity or the activation of some down-regulating mechanism), or the increased TR $\alpha$ expression levels after treatments were necessary for the maintenance of survival under the applied experimental conditions. It is also possible that robust increases in transcription (e.g., in Glia+: $\mathrm{E}_{2}+\mathrm{BPA}, \mathrm{T} 3+$ BPA, T4 + BPA and $\mathrm{E}_{2}+\mathrm{T} 3 / \mathrm{T} 4+\mathrm{BPA}$ ) may potentially exhaust cellular energy resources, thereby influencing other energy-dependent cellular processes as well.

Based on the disproportionality between transcription and translation, it can be speculated that one of the cellular adaptation mechanisms may manifest in the form of a high degree of plasticity in transcription (and possibly linked mechanisms, such as microRNA regulation, etc.) in order to maintain a relatively steady receptor protein expression. In fact, this idea may apply to our TR $\beta$ results as well.

\section{Thyroid hormone receptor beta (TR $\beta)$}

TR $\beta$ mRNA: Glia+ vs. Glia- (Fig. 3). Differences between the members of Glia+ and Glia- resemble, in many respects, to those found with regard to TR $\alpha$ mRNA. Differences between respective treatment groups in Glia+vs. Glia- suggest that the mediating role of glia in the regulation of neuronal TR $\beta$ receptor expression is ligand dependent, and also indicate that this mediating activity, in addition to the mere glial presentation of T3 (after conversion of T4 to T3) to neurones, contains additional functional element(s) as well, whose identification warrants further experiments.

TRß protein: Glia + vs. Glia- (Fig. 4), $m R N A$ vs. TR $\beta$ protein (Figs 3 and 4). The overall pattern of TR $\beta$ protein expression values may suggest that there is no glial contribution in the determination of the actual TR $\beta$ protein expression levels. It is, therefore, important to consider the role of glia in the regulation of TR $\beta$ transcription, since the simple examination of potential glia effects on TR $\beta$ protein expression would be misleading.

It is also interesting that exposure to BPA, alone or in combination with any of the hormones used, leads to significantly elevated TR $\beta$ protein expression.

This finding suggests that BPA could influence TR $\beta$ protein in a hormone ligand-independent manner, as also indicated with regard to TR $\alpha$. Again, this conclusion would be misleading regarding the effects of BPA on TR $\beta$ protein expression; therefore, we conclude that BPA effects on transcription and translation should be comparatively evaluated to understand the complexity of BPA and maybe other ED effects on the regulation of TR expression. 


\section{Further considerations}

To the best of our knowledge, no clear definition of the differences between the functional roles of TR $\alpha$ and TR $\beta$ is available, most probably because of the usual co-activation of these receptors by their common ligands (Somogyi et al., 2011). There are, however, studies reporting on physiological functions partly regulated by either of these receptors. Based on knockout and knockin experiments, TR $\alpha$ was found to influence cardiac functions, thermogenesis, haematopoiesis, and the maturation of intestines and bones (O'Shea et al., 2005; Plateroti et al., 2006). TR $\beta$ is crucial for normal, physiological endocrine and sensory functions such as those regulated by the hypothalamic-pituitary-thyroid axis, hepatic reactions to T3, behaviour, audition, colour sensation, and tactile senses (Amma et al., 2001; Ng et al., 2001; Flores-Morales et al., 2002; Abel et al., 2003; Esaki et al., 2003; Siesser et al., 2005). TR $\alpha$ and TR $\beta$, however, can be co-expressed in the same tissues and can substitute for each other's function to a certain extent (Gothe et al., 1999). Considering the latter potency of TRs allow us to reasonably suggest that one or more regulatory mechanisms interposed between transcription and translation is/are affected by BPA exposure. This idea is supported by reported alterations in microRNA expression in human placenta cells (Avissar-Whiting et al., 2010), MCF-7 breast cancer cells (Tilghman et al., 2012) and ovine fetal ovary (Veiga-Lopez et al., 2013) after BPA exposure.

We are aware that the in vitro conditions may substantially modify physiological parameters. Yet, it is more than likely that the observed BPA effects, combined with numerous biologically linked mechanisms, also occur in vivo, with the notion that in vivo, TR $\beta$ expression is restricted to specific ontogenetic states and is highly tissue specific (Bradley et al., 1994). Altogether, this idea is consonant with results from animal models that have shown that hypothyroidism during critical periods of development causes a variety of abnormalities in the central nervous system (Pasquini and Adamo, 1994; Martinez-Galan et al., 1997; Simorangkir et al., 1997), and that TR $\alpha$ and TR $\beta$ can compensate for each other's hypofunction. Finally, it should be noted that a growing body of evidence exists to show that BPA and other EDs increase intracellular reactive oxygen species and generate oxidative stress conditions in mitochondria and endoplasmic reticulum (Huc et al., 2012; Babu et al., 2013).

The present results clearly indicate that BPA interferes with the normal hormonal regulation of TR expression and thereby may lead to yet unknown biological consequences, either beneficial or adverse, in the developing cerebellum.

\section{Acknowledgements}

This work was supported by grants OTKA 104982 to T. Bartha and OTKA 81745 and OTKA 115613 to A. Zsarnovszky (from the National Research, Development and 
Innovation Fund, Hungary); Ministry of Human Capacities, Research Centre of Excellence Fund 8526-5/2015/TUDPOL (Hungary); and Research Centre of Excellence Fund 11476-3/2016/FEKUT (Hungary, to A. Zsarnovszky). This research was supported by the 11475-4/2016/FEKUT grant of the Hungarian Ministry of Human Resources.

\section{References}

Abel, E. D., Moura, E. G., Ahima, R. S., Campos-Barros, A., Pazos-Moura, C. C., Boers, M. E., Kaulbach, H. C., Forrest, D. and Wondisford, F. E. (2003): Dominant inhibition of thyroid hormone action selectively in the pituitary of thyroid hormone receptor-beta null mice abolishes the regulation of thyrotropin by thyroid hormone. Mol. Endocrinol. 17, 1767-1776.

Amma, L. L., Campos-Barros, A., Wang, Z. and Forrest, D. (2001): Distinct tissue-specific roles for thyroid hormone receptors beta and alphal in regulation of type 1 deiodinase expression. Mol. Endocrinol. 15, 467-475.

Avissar-Whiting, M., Veiga, K. R., Uhl, K. M., Maccani, M. A., Gagne, L. A., Moen, E. L. and Marsit, C. J. (2010): Bisphenol A exposure leads to specific microRNA alterations in placental cells. Reprod. Toxicol. 29, 401-406.

Babu, S., Uppu, S., Claville, M. O. and Uppu, R. M. (2013): Prooxidant actions of bisphenol A (BPA) phenoxyl radicals: implications to BPA-related oxidative stress and toxicity. Toxicol. Mech. Methods 23, 273-280.

Belcher, S. M. (2008): Rapid signaling mechanisms of estrogens in the developing cerebellum. Brain Res. Rev. 57, 481-492.

Belcher, S. M. and Zsarnovszky, A. (2001): Estrogenic actions in the brain: estrogen, phytoestrogens, and rapid intracellular signaling mechanisms. J. Pharmacol. Exp. Ther. 299, 408-414.

Billon, N., Jolicoeur, C., Tokumoto, Y., Vennstrom, B. and Raff, M. (2002): Normal timing of oligodendrocyte development depends on thyroid hormone receptor alpha 1. The EMBO Journal 21, 6452-6460.

Bradley, D. J., Towle, H. C. and Young, W. S. 3rd (1994): Alpha and beta thyroid hormone receptor (TR) gene expression during auditory neurogenesis: evidence for TR isoform-specific transcriptional regulation in vivo. Proc. Natl. Acad. Sci. USA 91, 439-443.

Delfosse, V., Grimaldi, M., Maire, A., Bourguet, W. and Balaguer, P. (2014): Nuclear receptor profiling of bisphenol-A and its halogenated analogues. Vitam. Horm. 94, 229-251.

Esaki, T., Suzuki, H., Cook, M., Shimoji, K., Cheng, S. Y., Sokoloff, L. and Nunez, J. (2003): Functional activation of cerebral metabolism in mice with mutated thyroid hormone nuclear receptors. Endocrinology 144, 4117-4122.

Fan, X., Xu, H., Warner, M. and Gustafsson, J. A. (2010): ERbeta in CNS: new roles in development and function. Prog. Brain Res. 181, 233-250.

Fauquier, T., Chatonnet, F., Picou, F., Richard, S., Fossat, N., Aguilera, N., Lamonerie, T. and Flamant, F. (2014): Purkinje cells and Bergmann glia are primary targets of the TR $\alpha 1$ thyroid hormone receptor during mouse cerebellum postnatal development. Development 141, 166-175.

Flores-Morales, A., Gullberg, H., Fernandez, L., Stahlberg, N., Lee, N. H., Vennstrom, B. and Norstedt, G. (2002): Patterns of liver gene expression governed by TRbeta. Mol. Endocrinol. 16, 1257-1268.

Gentilcore, D., Porreca, I., Rizzo, F., Ganbaatar, E., Carchia, E., Mallardo, M., De Felice, M. and Ambrosino, C. (2013): Bisphenol A interferes with thyroid specific gene expression. Toxicology 304, 21-31.

Gothe, S., Wang, Z., Ng, L., Kindblom, J. M., Barros, A. C., Ohlsson, C., Vennstrom, B. and Forrest, D. (1999): Mice devoid of all known thyroid hormone receptors are viable but ex- 
hibit disorders of the pituitary-thyroid axis, growth, and bone maturation. Genes Dev. 13, $1329-1341$.

Huc, L., Lemarie, A., Gueraud, F. and Helies-Toussaint, C. (2012): Low concentrations of bisphenol A induce lipid accumulation mediated by the production of reactive oxygen species in the mitochondria of HepG2 cells. Toxicol. In Vitro 26, 709-717.

Iwamuro, S., Yamada, M., Kato, M. and Kikuyama, S. (2006): Effects of bisphenol A on thyroid hormone-dependent up-regulation of thyroid hormone receptor alpha and beta and downregulation of retinoid X receptor gamma in Xenopus tail culture. Life Sci. 79, 2165-2171.

Kariv, R., Enden, A., Zvibel, I., Rosner, G., Brill, S., Shafritz, D. A., Halpern, Z. and Oren, R. (2003): Triiodothyronine and interleukin-6 (IL6) induce expression of HGF in an immortalized rat hepatic stellate cell line. Liver Int. 23, 187-193.

Leonard, J. L. (1988): Dibutyryl cAMP induction of type II 5'deiodinase activity in rat brain astrocytes in culture. Biochem. Biophys. Res. Commun. 151, 1164-1172.

Leonard, J. L. (2008): Non-genomic actions of thyroid hormone in brain development. Steroids 73, $1008-1012$.

Martinez-Galan, J. R., Pedraza, P., Santacana, M., Escobar del Ray, F., Morreale de Escobar, G. and Ruiz-Marcos, A. (1997): Early effects of iodine deficiency on radial glial cells of the hippocampus of the rat fetus. A model of neurological cretinism. J. Clin. Invest. 99, 2701-2709.

Mathisen, G. H., Yazdani, M., Rakkestad, K. E., Aden, P. K., Bodin, J., Samuelsen, M., Nygaard, U. C., Goverud, I. L., Gaarder, M., Loberg, E. M., Bolling, A. K., Becher, R. and Paulsen, R. E. (2013): Prenatal exposure to bisphenol A interferes with the development of cerebellar granule neurons in mice and chicken. Int. J. Dev. Neurosci. 31, 762-769.

Miodovnik, A., Edwards, A., Bellinger, D. C. and Hauser, R. (2014): Developmental neurotoxicity of ortho-phthalate diesters: review of human and experimental evidence. Neurotoxicology 41, 112-122.

Nakagawa, Y. and Tayama, S. (2000): Metabolism and cytotoxicity of bisphenol A and other bisphenols in isolated rat hepatocytes. Arch. Toxicol. 74, 99-105.

Ng, L., Pedraza, P. E., Faris, J. S., Vennstrom, B., Curran, T., Morreale de Escobar, G. and Forrest, D. (2001): Audiogenic seizure susceptibility in thyroid hormone receptor beta-deficient mice. Neuroreport 12, 2359-2362.

O’Shea, P. J., Bassett, J. H., Sriskantharajah, S., Ying, H., Cheng, S. Y. and Williams, G. R. (2005): Contrasting skeletal phenotypes in mice with an identical mutation targeted to thyroid hormone receptor alpha1 or beta. Mol. Endocrinol. 19, 3045-3059.

Pasquini, J. M. and Adamo, A. M. (1994): Thyroid hormones and the central nervous system. Dev. Neurosci. 16, 1-8.

Plateroti, M., Kress, E., Mori, J. I. and Samarut, J. (2006): Thyroid hormone receptor alpha1 directly controls transcription of the beta-catenin gene in intestinal epithelial cells. Mol. Cell. Biol. 26, 3204-3214.

Scalise, T. J., Győrffy, A., Tóth, I., Kiss, D. S., Somogyi, V., Goszleth, G., Bartha, T., Frenyó, L. V. and Zsarnovszky, A. (2012): Ligand-induced changes in oestrogen and thyroid hormone receptor expression in the developing rat cerebellum: A comparative quantitative PCR and Western blot study. Acta Vet. Hung. 60, 263-284.

Sheng, Z. G., Tang, Y., Liu, Y. X., Yuan, Y., Zhao, B. Q., Chao, X. J. and Zhu, B. Z. (2012): Low concentrations of bisphenol A suppress thyroid hormone receptor transcription through a nongenomic mechanism. Toxicol. Appl. Pharmacol. 259, 133-142.

Shikimi, H., Sakamoto, H., Mezaki, Y., Ukena, K. and Tsutsui, K. (2004): Dendritic growth in response to environmental estrogens in the developing Purkinje cell in rats. Neurosci. Lett. 364, 114-118.

Siesser, W. B., Cheng, S. Y. and McDonald, M. P. (2005): Hyperactivity, impaired learning on a vigilance task, and a differential response to methylphenidate in the TRbetaPV knock-in mouse. Psychopharmacology (Berl.) 181, 653-663. 
Simorangkir, D. R., Wreford, N. G. and De Kretser, D. M. (1997): Impaired germ cell development in the testes of immature rats with neonatal hypothyroidism. J. Androl. 18, 186-193.

Somogyi, V., Györffy, A., Scalise, T. J., Kiss, D. S., Goszleth, G., Bartha, T., Frenyó, V. L. and Zsarnovszky, A. (2011): Endocrine factors in the hypothalamic regulation of food intake in females: a review of the physiological roles and interactions of ghrelin, leptin, thyroid hormones, oestrogen and insulin. Nutr. Res. Rev. 24, 132-154.

Tilghman, S. L., Bratton, M. R., Segar, H. C., Martin, E. C., Rhodes, L. V., Li, M., McLachlan, J. A., Wiese, T. E., Nephew, K. P. and Burow, M. E. (2012): Endocrine disruptor regulation of microRNA expression in breast carcinoma cells. PLoS One 7, e32754.

Vasudevan, N., Koibuchi, N., Chin, W. W. and Pfaff, D. W. (2001): Differential crosstalk between estrogen receptor (ER)alpha and ERbeta and the thyroid hormone receptor isoforms results in flexible regulation of the consensus ERE. Brain Res. Mol. Brain Res. 95, 9-17.

Veiga-Lopez, A., Luense, L. J., Christenson, L. K. and Padmanabhan, V. (2013): Developmental programming: gestational bisphenol-A treatment alters trajectory of fetal ovarian gene expression. Endocrinology 154, 1873-1884.

Wong, J. K., Kennedy, P. R. and Belcher, S. M. (2001): Simplified serum- and steroid-free culture conditions for the high-throughput viability analysis of primary cultures of cerebellar neurons. J. Neurosci. Methods 110, 45-55.

Wong, J. K., Le, H. H., Zsarnovszky, A. and Belcher, S. M. (2003): Estrogens and ICI182,780 (Faslodex) modulate mitosis and cell death in immature cerebellar neurons via rapid activation of p44/p42 mitogen-activated protein kinase. J. Neurosci. 23, 4984-4995.

Xu, X., Liu, Y., Sadamatsu, M., Tsutsumi, S., Akaike, M., Ushijima, H. and Kato, N. (2007): Perinatal bisphenol A affects the behavior and SRC-1 expression of male pups but does not influence on the thyroid hormone receptors and its responsive gene. Neurosci. Res. 58, 149-155.

Xu, X., Lu, Y., Zhang, G., Chen, L., Tian, D., Shen, X., Yang, Y. and Dong, F. (2014): Bisphenol A promotes dendritic morphogenesis of hippocampal neurons through estrogen receptormediated ERK1/2 signal pathway. Chemosphere 96, 129-137.

Yamaguchi, H., Zhu, J., Yu, T., Sasaki, K., Umetsu, H., Kidachi, Y. and Ryoyama, K. (2006): Low-level bisphenol A increases production of glial fibrillary acidic protein in differentiating astrocyte progenitor cells through excessive STAT3 and Smad1 activation. Toxicology 226, 131-142.

Zhang, W. Z., Yong L., Jia, X. D., Li, N. and Fan, Y. X. (2013): Combined subchronic toxicity of bisphenol A and dibutyl phthalate on male rats. Biomed. Environ. Sci. 26, 63-69.

Zhao, X., Lorenc, H., Stephenson, H., Wang, Y. J., Witherspoon, D., Katzenellenbogen, B., Pfaff, D. and Vasudevan, N. (2005): Thyroid hormone can increase estrogen-mediated transcription from a consensus estrogen response element in neuroblastoma cells. Proc. Natl. Acad. Sci. USA 102, 4890-4895.

Zoeller, R. T. (2005): Environmental chemicals as thyroid hormone analogues: new studies indicate that thyroid hormone receptors are targets of industrial chemicals? Mol. Cell. Endocrinol. 242, 10-15.

Zoeller, R. T., Bansal, R. and Parris, C. (2005): Bisphenol-A, an environmental contaminant that acts as a thyroid hormone receptor antagonist in vitro, increases serum thyroxine, and alters $\mathrm{RC} 3$ /neurogranin expression in the developing rat brain. Endocrinology 146, 607-612.

Zsarnovszky, A., Földvári, E. G., Rónai, Z., Bartha, T. and Frenyó, L. V. (2007): Oestrogens in the mammalian brain: from conception to adulthood - a review. Acta Vet. Hung. 55, 333-347.

Zsarnovszky, A., Le, H. H., Wang, H. S. and Belcher, S. M. (2005): Ontogeny of rapid estrogenmediated extracellular signal-regulated kinase signaling in the rat cerebellar cortex: potent nongenomic agonist and endocrine disrupting activity of the xenoestrogen bisphenol A. Endocrinology 146, 5388-5396. 